\title{
Differential Algorithm Based Intelligent Protection Scheme for Microgrid
}

\author{
Pooja Khandare, S.A.Deokar, A.M.Dixit
}

\begin{abstract}
Proposed scheme presents intelligent technique in protection of microgrid. This paper gives new approach in feature extraction of faulted current signal using Discrete Wavelet Transform. Furthermore different parameters like TMS(Time Measurment setting),PSM (Plug setting Multiple) and CTD (coordination time Duration) are computed from featured faulty current. This course of action used to build genetic differential algorithm for deciding best suitable pair of relay with concept of "survival of fittest". IEEE 9 bus system is considered for studding different types of faults for utilityconnected and islanded mode. Initially primary pair of relay is activated and secondary protection operates on failure of primary. This study gives effective solution for fast operation of pair of relay in optimized time.
\end{abstract}

Keywords: Protection; Relay coordination; Micro grid; fault detection; Discrete Wavelet Transform (DWT)

\section{INTRODUCTION}

Fossils fuels are vanishing day by day hence need of micro grid is increasing. Penetration of renewable energy sources and Distributed generators (DGs) in grid reduces greenhouse effect and give solution to high energy demand and depletion of artificial sources[1-4]. Micro grid gives quality of supply to all types of load commercial as well as household in rural and urban areas [4].In remote areas where electricity is not reached because of natural calamities and atmosphere micro grid is best solution. Micro grid System works for both mode of operation grid connected as well as islanded mode [5].[6] gives digital protection scheme for micro grid using wavelet transform which does not consider Grid connected and islanded mode of operation. Author in [8] gives Time-frequency transform-based differential schemefor micro grid protectionstudied both modes and HIF but feature extraction take place with help of differential energy and Threshold which results in increase in tripping time of relay. [10]

Revised Manuscript Received on July 25, 2019.

Pooja Khandare,Dr.S.A.Deokar,Dr.A.M.Dixit

Poojakhandare24@gmail.com,S_deokar02@rediffmail.com,

adixit@gmail.com

Ph.D student,Department of Technolgy,Pune

Campus Director,ZES'S ZCOER,Pune ,India

B201, Veerodaya society, new grant road Kharadi,Pune 411041
An adaptive overcurrent protection scheme based on the synchronous phase measurement is proposed for different operation modes in microgrid but not studied for moth operating modes. [14]fuzzy and neuro based optimization techniques used to create problem for relay coordination predefined for various issued therefore if new issue obtained with system ,coordination fails[3]-[4]

microgrid provides feasible solution for forthcoming problems like greenhouseeffect, growing energy demand, and the depletion of conventional fossil fuel energy sources.Many researchers give different techniques in feature extraction of fault current in microgrid.Author [1] suggest protection scheme which utilizes the principles of synchronized phasor measurements and microprocessor relays to detect all types of fault conditions in case of both modes of operation but as communication is included which results in increases in cost. [2] Gives sequence component based feature extraction protection but the robustness and reliability of the proposed schemes need to improve.Curve fitting is one method in which inverse time operating relation are obtained on graph for many faults. Linear and nonlinear characteristics are tested for relay coordination with different operating curves [5]but accuracy of this method is very poor. Non Linear optimization techniques [16][17] in which problem is formulated using nonlinear programming. Both TDS and PSM are selected efficiently; minima trap can be obtained in this method. Hybrid optimization method which is combination of Analytical and optimization method capable of solving relay coordination problem for big interconnected system but worked with fixed topology[15]-[18].There is need to discover intelligent scheme for microgrid protection with optimization techniques.

\section{SYSTEM DESCRIPTION}

IEEE-9 bus system is converted to hybrid microgrid by connecting two solar one wind and one diesel generator set. Normal grid is fed with two feeder $115 \mathrm{kV}, \mathrm{X} / \mathrm{R}$ ratio $=6, \mathrm{MVA}=500 \mathrm{MVA}$. The line impedance is $0.1529+\mathrm{j} 0.1406 \Omega / \mathrm{km}$, all lines are $500 \mathrm{~m}$ long. Transformer connected to point of coupling is with rating 20 MVA, $115 \mathrm{kV} / 12.47 \mathrm{kV}$.Ratings of DG are 480V, 20 MVA, $\mathrm{xd}^{\prime}=0.11$ with transformer rating 20 MVA, $12.47 \mathrm{kV} / 480 \mathrm{~V}$.load capacity is given by 2 MVA, 0.9 system is shown in fig. 1 


\section{Differential Algorithm Based Intelligent Protection Scheme for Microgrid}

When renewable sources are not connected to system single overcurrent relay are sufficient to protect system from faults. But with penetration of DGs it becomes complex network as flow of current is bidirectional. Hence primary and secondary protection is necessary. Comprehensive simulation studies are conducted to verify the efficiency of the proposed protection strategy in the MATLAB environment in different fault scenarios.

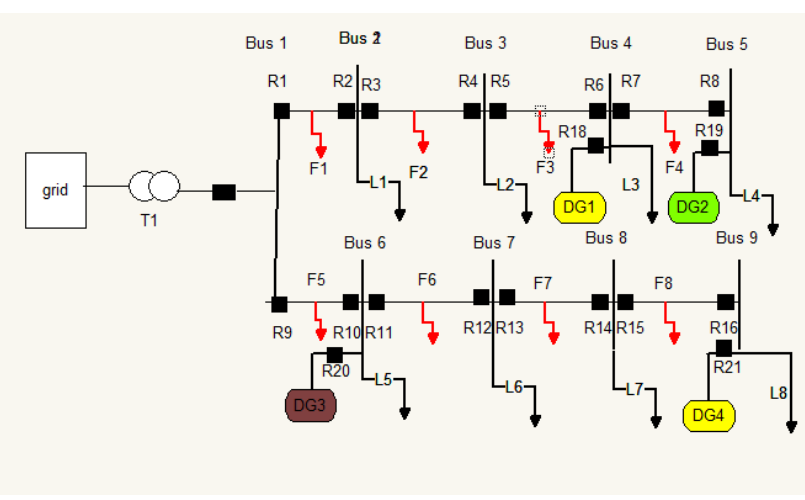

Fig 1:- IEEE 9 bus system with integrated source

Comprehensive simulation studies are carried out to verify the effectiveness of the proposed protection strategy under different fault scenarios, in the MATLAB environment. Fig-2 shows different fault currents at 5 buses in different operating modes for LG fault. It is noticed that fault current in utility connected mode is higher than islanded mode .As fault current is proportional to short- circuit power of the grid and inverse to short-circuit impedance seen by the fault. Overall there is noteworthy difference in two operating modes. As fault current contributed by utility is more than islanded mode. Table-I shows pair of primary and Secondary relay in utility connected and islanded mode.Microgrid Protection strategy must respond positively and offer safe and reliable operation against fault .Considering these all challenges this paper offer new approach of integrated DWT and differential algorithm technique for secured and safe operation of micro grid. The proposed scheme considers L-G shunt fault at various locations in grid connected and islanded mode at various location of distribution line. Fault current is processed through DWT feature extraction to extract delicate features and remove noise content from both ends of distribution line. These extracted features from DWT are used to build model with differential algorithm techniques and tripping command is issue to circuit breaker by choosing pair of primary and secondary relay.

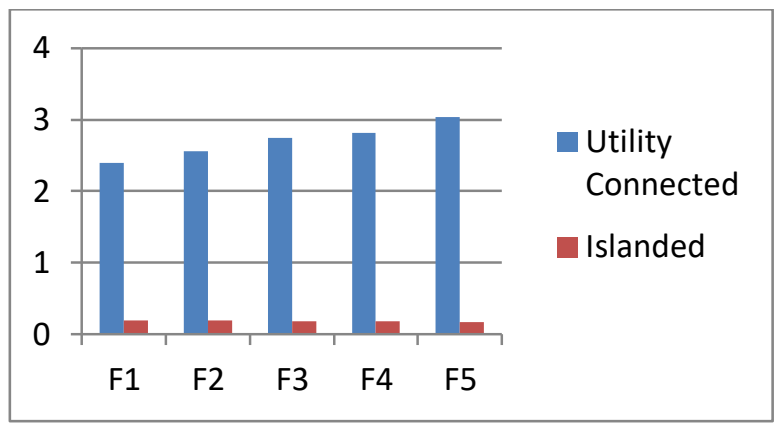

Fig 2:-current distribution in grid connected and Islanded mode

Table-I

Primary and backup relays for 5 bus in Utility connected and islanded mode

\begin{tabular}{|c|l|l|l|}
\hline Faults & \multicolumn{1}{|c|}{ Modes } & Primary Relay & Secondary Relay \\
\hline \multirow{2}{*}{ F1 } & Utility connected Mode & R1, R2 & R10, R17, R4 \\
\cline { 2 - 4 } & Islanded Mode & R1, R2 & R10, R4 \\
\hline \multirow{2}{*}{ F2 } & Utility connected Mode & R3, R4 & R1, R6 \\
\cline { 2 - 5 } & Islanded Mode & R3, R4 & R1, R6 \\
\hline \multirow{2}{*}{ F3 } & Utility connected Mode & R5, R6 & R3, R8, R18 \\
\cline { 2 - 5 } & Islanded Mode & R5, R6 & R3, R8, R18 \\
\hline \multirow{2}{*}{ F4 } & Utility connected Mode & R7, R8 & R5, R18, R19 \\
\cline { 2 - 5 } & Islanded Mode & R7, R8, & R5, R18, R19 \\
\hline \multirow{2}{*}{ F5 } & Utility connected Mode & R9, R10 & R2, R17, R12, R20 \\
\cline { 2 - 5 } & Islanded Mode & R9, R10 & R2, R12, R20 \\
\hline
\end{tabular}

\section{IMPLEMENTATION OF INTEGRATED DWT DIFFERENTIAL ALGORITHM}

A. Optimization Problem

Transfer coordination improvement issue can be planned as nonlinear programming issue whose principal point is to limit add up relay working time,(i,e total of the primary and secondary relay)Adaptive assurance methodology is utilized. Overcurrent relay which fill in as essential relay in its zone same relay is function as secondary relay when blame is in neighboring zone.

$$
F_{R}=\operatorname{Min} \sum_{i=1}^{n} \sum_{j=1}^{2} A_{i} T M S_{i}
$$

Where $F_{R}$ is relay function which has to be minimize $\mathrm{i}$ is faulty line or location identifier, $\mathrm{n}$ is total no of relay $\mathrm{j}$ is primary relay each fault have 2 primary relay.

$$
A_{i}=\frac{a}{\left\{\left(\frac{I S C}{I p}\right)^{b}-1\right\}}
$$


(2)

Where $\mathrm{a}$ and $\mathrm{b}$ overcurrent relay parameters that are depend on relay characteristics. Here value of $a$ and $b$ are set to 0.1401 and 0.0201 , respectively.

$\mathrm{I}_{\mathrm{sc}}$ : Fault current and Ip is relay pick up current.

TMS (Time Measurement setting) of relay

TMS and pick up current of relay are two parameter from which operating time of relay is optimized. Pick up current is defined as minimum value of short circuit current above which relay continues to operate.

Value of optimized PSM and TMS is given below in fig1. Coordinated relay settings result in operating time of relays which are satisfying all the necessary constraints applied to the relay coordination problem

\section{B. Constraint}

For proper coordination of relay some constraint should be applied on objective function if any criteria is not fulfilled then penalty is applied .To ensure reliable operation of microgrid primary protection must provide with secondary protection which will operate only when primary protection disappointed. However secondary protection sends tripping signal after 0.201 sec delay called as CTD (coordination time duration).

$$
\begin{aligned}
& B_{\text {ackup }}-P_{\text {rimary }} \geq C T D \\
& T M S_{\text {Imin }} \leq T M S \leq T M S_{\text {Imax }} \\
& I_{\text {pimin }} \leq I_{\text {pi }} I_{\text {pimax }}
\end{aligned}
$$

TMS and pick up current of relay are two parameter from which operating time of relay is optimized. $\mathrm{I}_{\mathrm{pr}}$ is calculated from minimum value of fault current above which relay starts to operate. Value of optimized PSM and TMS is given below in table -II. Coordinated relay settings result in operating time of relays which are satisfying all the necessary constraints applied to the relay coordination problem

Table II

Relay settings given in terms of PSM and TMS

\begin{tabular}{|c|c|c|c|c|c|}
\hline $\begin{array}{c}\text { Fault } \\
\text { Location }\end{array}$ & PSM & TMS & $\begin{array}{c}\text { Fault } \\
\text { Location }\end{array}$ & PSM & TMS \\
\hline R1 & 0.0033 & 0.221 & R11 & 0.0020 & 0.1390 \\
\hline R2 & 0.0039 & 0.282 & R12 & 0.0199 & $0.522-$ \\
\hline R3 & 0.0026 & 0.139 & R13 & 0.0113 & 0.1570 \\
\hline R4 & 0.004 & 0.344 & R14 & 0.0117 & 0.3110 \\
\hline R5 & 0.0027 & 0.081 & R15 & 0.0114 & 0.500 \\
\hline R6 & 0.0031 & 0.364 & R16 & 0.0053 & 0.3630 \\
\hline R7 & 0.0095 & 0.5 & R17 & 0.008 & 0.944 \\
\hline R8 & 0.0085 & 0.491 & R18 & 0.0096 & 0.923 \\
\hline R9 & 0.06 & 0.356 & R19 & 0.0079 & 0.7150 \\
\hline R10 & 0.0032 & 0.272 & R20 & 0.0079 & 0.9150 \\
\hline & & & R21 & 0.034 & 0.9990 \\
\hline
\end{tabular}

\section{Feature Extraction}

DWT is used to estimate fundamental features from short circuit current by using db4 mother wavelet [13].Feature extraction for LG fault with 4 level coefficient decomposition is shown in fig3.After extraction of feature with DWT from faulty signal, primary protection starts operating as shown in fig 4 .PR1 and
PR2 are primary relay for LG fault. If primary protection fails BU1 and BU2 starts operating with some time interval. 


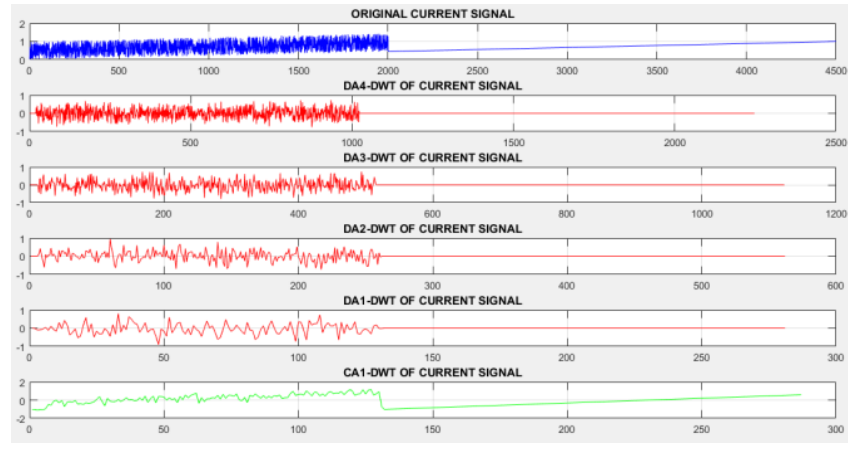

Fig 3:-feature extraction with DWT

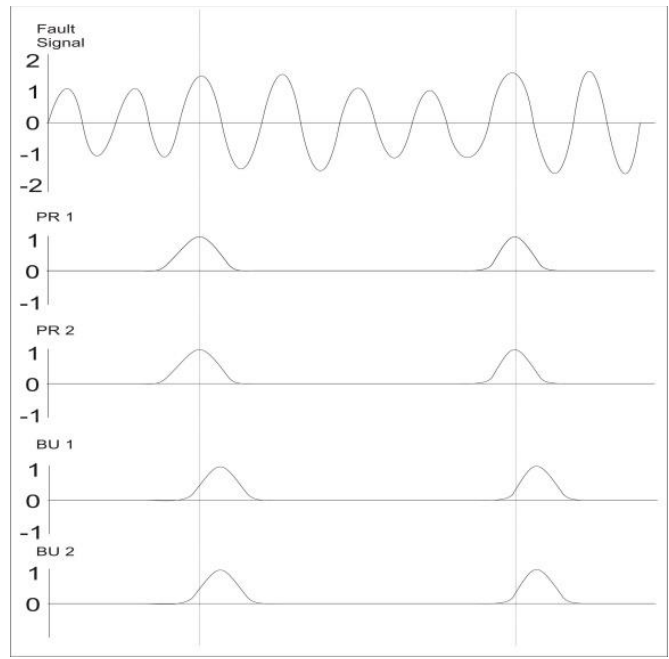

Fig 4:-Operation of primary and backup relay

\section{Differential Algorithm}

"survival of fittest "is one of the evolutionary approach for optimization method.it start with search of random set of populations , and solution with better fitness are selected as parent to produce next generation.

The software is implemented according to

the following steps:

I) Step 1.Intialization of all parameters, like population size, no of generation, cross over probability, scaling factor

II) Step 2.Generate first Iteration

III) Step 3. Generate different target vector set randomly for size $\mathrm{S}$ corresponding to the variables such as (PSM, TMS) which has to be optimized. Target vector set: Vi,P; $i=1,2,3, \ldots, \mathrm{S}$

IV) Step 4. With the help of vector set calculate objective function given with reference to eq-(1)

V) Step 5.Mutation :For a given set of vector Vi,P , generate 3 random definite vectors (Vr1,P, $\mathrm{Vr} 2, \mathrm{P}, \mathrm{Vr} 3, \mathrm{P}$ and $\mathrm{Vr} 4, \mathrm{P}$ Generate mutant vector for target vector.

$\mathrm{X}_{\mathrm{i}, \mathrm{P}}=\mathrm{V}_{\text {best }, \mathrm{P}}+\mathrm{f}_{1}\left(\mathrm{~V}_{\mathrm{r} 1 \mathrm{i}, \mathrm{P}}-\mathrm{V}_{\mathrm{r} 2 \mathrm{i}, \mathrm{P}}\right)+\mathrm{f}_{2}\left(\mathrm{~V}_{\mathrm{r} 3 \mathrm{i}, \mathrm{P}}-\right.$ Vr4i,P

VII) Step 6.Crossover: on the basis of crossover probability Obtain trial set of vector by replacing some of the mutant vectors obtain with step 5 by target vector

VIII) Step 7.Selection: Merge vector which we assume initially with target set of vector.Compare merged vector set and sort the vector set in ascending order (in accordance to the minimum objective function value). Sorted vector set is of doubled population size Select vector set of P-size (optimum values) and remove the rest values

IX) Step 8.In sorted vector set of $\mathrm{S}$ size if maximum generation is reached then Select Vector (variable value) which results in the minimum value of objective function. Obtain $\mathrm{V}_{\text {best }}$ individual and stop the process and if maximum generation is not reached then sorted vector set-Target vector for next generation and increment generation by 1 and directly jump to step 3 and repeat the algorithm. Relay use wavelet technique in detection of fault. Different conditions like healthy and faulty are checked within microgrid.Short circuit signal from faulty line are input to the intelligent relay.

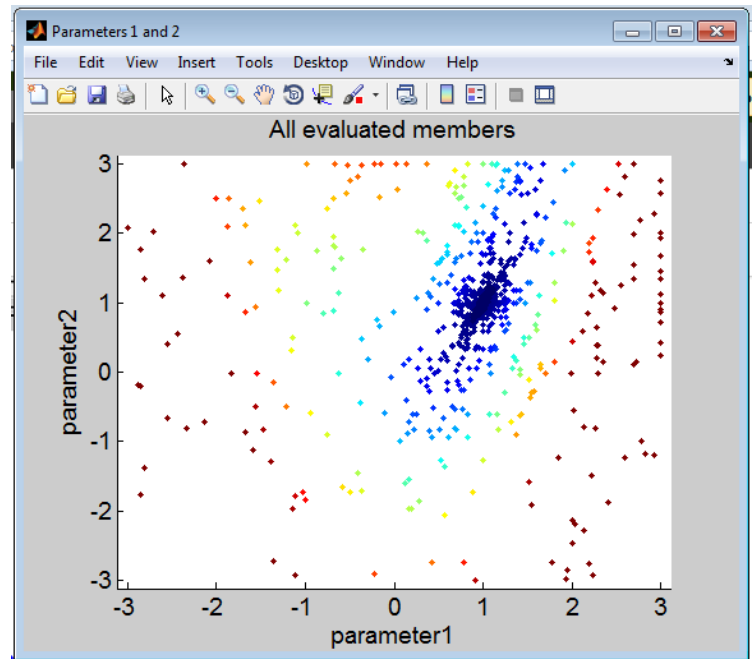

Fig 4:-Survival of Fittest technique for selection of pair of relay

\section{RESULT AND ANALYSIS}

Execution examination between overcurrent Relay strategy [7] and ref [9] which utilized DFT system for highlight extraction is contrasted with proposed technique. Table III gives correlation for short out current of over three techniques. Correlation Results demonstrates that in ref [7] no component extraction will complete straightforwardly hamper use for hereditary calculation. What's more, in ref [9] DFT is utilized for highlight extraction; information mining enhancement system is utilized for further figuring. Table IV gives operating time required for all three methods. Which lessoned proposed technique is more efficient than compared methods.

Some statistical definitions are present from which performance based result can be compared. Reliability is one of them which is defined as Total number of fault cases assumed/Total number of real fault cases happen. Performance comparison in Overcurrent Relay with Differential Algorithm,DFT with Data mining

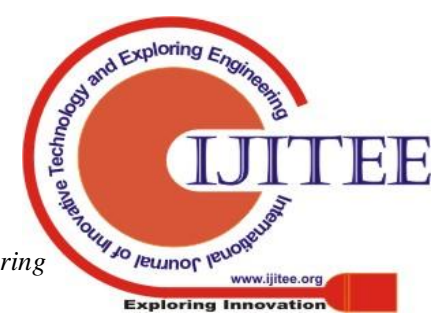


Table III

Comparison of Short circuit current with Different Feature Extraction Technique

\begin{tabular}{|c|c|c|c|c|c|c|c|c|c|c|c|c|}
\hline Fault & \multicolumn{4}{|c|}{ Over Current relay[7] } & \multicolumn{4}{|c|}{ DFT[9] } & \multicolumn{4}{|c|}{ DWT[proposed method] } \\
\hline & Utility co & ected & Islandec & & Utility & nected & Islanc & & Utility & ected & Island & \\
\hline F1 & 61.602 & 40.774 & 41.704 & 40.774 & 8.08 & 2.44 & 1.06 & 3.31 & 2.4 & 2.45 & 0.191 & 0.183 \\
\hline $\mathrm{F} 2$ & 57.722 & 42.651 & 39.881 & 42.651 & 8.41 & 2.06 & 1.83 & 2.12 & 2.56 & 2.65 & 0.19 & 0.195 \\
\hline F3 & 54.160 & 22.826 & 38.161 & 44.628 & 4.64 & 1.08 & 2.01 & 1.38 & 2.74 & 2.80 & 0.18 & 0.196 \\
\hline $\mathrm{F} 4$ & 72.1362 & 43.629 & 58.234 & 22.826 & 4.67 & 1.84 & 2.21 & 1.24 & 2.82 & 2.95 & 0.185 & 0.194 \\
\hline F5 & 58.8486 & 21.826 & 39.000 & 43.629 & 3.12 & 2.21 & 1.69 & 1.76 & 3.04 & 3.07 & 0.171 & 0.187 \\
\hline
\end{tabular}

Table IV

Comparison of operating time

\begin{tabular}{|c|c|c|c|}
\hline \multirow{2}{*}{ Fault } & \multicolumn{3}{|c|}{ Operating Time } \\
\cline { 2 - 4 } & $\begin{array}{c}\text { Overcurrent Relay with } \\
\text { Differential Algorithm }\end{array}$ & $\begin{array}{c}\text { DFT with Data mining } \\
\text { Techniques }\end{array}$ & $\begin{array}{c}\text { DWT with Differential } \\
\text { Algorithm }\end{array}$ \\
\hline \multirow{2}{*}{ LG fault } & 0.35 Cycle & 0.2 Cycle & 0.1 Cycle \\
\hline
\end{tabular}

Table V

Performance Comparison in terms of Reliability

\begin{tabular}{|c|c|c|}
\hline Techniques & Grid Connected & Islanded \\
\hline Overcurrent Relay with Differential Algorithm & $79 \%$ & $63 \%$ \\
\hline DFT with Data mining Techniques & $97.6 \%$ & $98 \%$ \\
\hline DWT with Differential Algorithm & $98 \%$ & $99 \%$ \\
\hline
\end{tabular}

\section{CONCLUSION}

This research proposes a genetic algorithm model-based differential intelligent protection scheme for microgrid protection. The given scheme develops protection optimization function for the microgrid operating at utility connected and Islanded mode. The differential features extraction at respective buses with DWT is used to build the Survival of fittest models, which are used for a final relaying decision. The proposed DWT differential algorithm is extensively tested on the standard IEEE 9 bus microgrid model. Comparison result show that in overcurrent and DFT method proposed method takes less operating time. The performance comparison with existing relays indicates that the proposed scheme can provide a highly reliable and effective protection measure for the microgrid.

\section{REFERENCES}

1. Eric Sortomme, S. S. Venkata, and Joydeep Mitra," Microgrid Protection Using Communication-Assisted Digital Relays "IEEE TRANSACTIONS ON POWER DELIVERY, VOL. 25, NO. 4, OCTOBER 2010

2. Sachit Gopalan, Victor Sreeram, Herbert Iu Yateendra Mishra "An Improved Protection Strategy for Microgrids" 2013 4th IEEE PES Innovative Smart Grid Technologies Europe (ISGT Europe), October 6-9, Copenhagen

3. M. Stadler, A. Siddiqui, C. Marnay, H. Aki, and J. Lai, "Control of greenhouse gas emissions by optimal DER technology investment and energy management in zero-net-energy buildings," Eur. Trans. Electr. Power, vol. 21, no. 2, pp. 1291-1309, Mar. 2011.

4. G. Venkataramanan and C. Marnay, "A larger role for microgrids," IEEE Power Energy Mag., vol. 6, no. 3, pp. 78-82, May/Jun. 2008.

5. Bramha S.M and Girgis A"development of adaptive protection scheme for distribution system with high penetration of distributed denerations"IEEE Trans,power Del 2004,19(1)pp,56-63

6. P.kanakasabapathy,Meenakshi Mohan ,Digital protection Sceheme for microgrid Protection 978-1-4799-8364-3/15/\$31.00_c 2015 IEEE

7. Ankita Sharma and B. K. Panigrahi,“optimal Relay Coordination suitable for Grid-Connected and Islanded operational modes of Microgrid" Senior Member, IEEE IEEE INDICON 2015 1570185643

8. Susmita Kar, Subhransu Rajan Samantaray Time-frequency transform-based differential scheme for microgrid protection IET Gener. Transm. Distrib., 2014, Vol. 8, Iss. 2, pp. 310-320

9. Susmita Kar, S. R. Samantaray, and M. Dadash Zadeh Data-Mining Model Based Intelligent Differential Microgrid Protection Scheme IEEE SYSTEMS JOURNAL1932-8184 @ 2015 IEEE.

10. Lin, Hengwei; Guerrero, Josep M.; Jia, Chenxi; Tan, Zheng-Hua; Quintero, Juan CarlosVasquez; Liu, Chengxi "Adaptive Overcurrent Protection for Microgrids in Extensive Distribution Systems" Proceedings of IECON 2016:

11. E. Casagrande and L. N. Woon, "A differential sequence component protection scheme for 
micro-grids with inverter based distributed generators," IEEE Trans. Smart Grid., vol. 5, no. 1, pp. 29-37, Jan. 2014.

12. P. Mahat, Z. Chen, B. Bak-Jensen, and C. L. Bak, "A simple adaptive over current protection of distributed systems with distributed generations," IEEE Trans. Smart Grid, vol. 2, no. 3, pp. 428-437, Sep. 2011.

13. Debi Prasad Mishra, Subhransu Ranjan Samantaray "A Combined Wavelet and Data-Mining BasedIntelligent Protection Scheme for Microgrid"IEEE TRANSACTIONS ON SMART GRID, VOL. 7, NO. 5, SEPTEMBER 2016

14. Q. H. Wu, J. F. Zhang, and D. J. Zhang, "Ultra-high-speed directional protection of transmission lines using mathematical morphology," IEEE Trans. Power Del., vol. 18, no. 4, pp. 11271133, Oct. 2003.

15. Keng-Yu Lien Shi-Lin Chen, Duong Minh Bui, Wei-Xiang Zhao "Fast Computing Algorithm for Microgrid Fault Protection System Using Communication-Assisted Digital Relays and Initially Experimental Results"

16. Mehdi monadi and catalin gavriluta "A communication assisted protection for MVDC distribution systems with distributed generation" IEEE transaction

17. Subhashree chaudhary ,Leesa mohapatra"A comprehensive review on modelling,control,protection and future prospectus of microgrid"', Ed. 3, Electrical Distribution-System Protection, Cooper Industries, 1990.

18. F. H. Magnago and A. Abur, "Fault location using wavelets," IEEE Trans. Power Del., vol. 13, no. 4, pp. 1475-1480, Oct. 1998. 